\title{
PERANCANGAN ALGORITMA PENJADWALAN KULIAH YANG MEMPERTIMBANGKAN DAMPAK TERHADAP LINGKUNGAN DENGAN MENGGUNAKAN CONSTRAINT PROGRAMMING
}

\author{
Sriyanto*), Hasan Mastrisiswadi \\ Program Studi Teknik Industri, Fakultas Teknik, Universitas Diponegoro, \\ Jl. Prof. Soedarto, SH, Kampus Undip Tembalang, Semarang, Indonesia 50275
}

\begin{abstract}
Abstrak
Penjadwalan kuliah yang bersifat dinamis ini secara langsung menjadi faktor tingginya kepadatan transportasi di lingkungan universitas. Tingginya intensitas berkendara di lingkungan Universitas yang merupakan akibat dari pola penjadwalan kuliah, tentunya diikuti dengan tingginya emisi yang dihasilkan oleh kendaraan yang digunakannya. Belum adanya pola penjadwalan kuliah yang memperhatikan dampak terhadap lingkungan akan tentu saja akan memperkeruh lingkungan ini dengan emisi yang terus dibuang oleh manusia. Dengan memasukkan konsep constraint programming dengan pembatas yang mempertimbangkan dampak terhadap lingkungan dalam penjadwalan kuliah diharapkan mampu mengurangi emisi kendaraan peserta kuliah. Jurusan Teknik Sipil, sebagai jurusan tertua dan terbesar di Fakultas Teknik Universitas Diponegoro dengan jumlah mahasiswa rata-rata 280 tiap angkatannya menjadi objek dalam penerapan rancangan algoritma yang dibuat karena memiliki jumlah kendaraan yang paling banyak dibandingkan jurusan lain di Fakultas Teknik. Adapun hasil dari penerapan algoritma ini, mampu mereduksi jumlah emisi sebesar 50\% untuk angkatan 2011 dan 2010 dan bahkan 66,6\% untuk mahasiswa angkatan 2009.
\end{abstract}

Kata kunci: penjadwalan kuliah; constraint programming; emisi

\begin{abstract}
The dynamic of course scheduling is a direct factor to the high density of transport in the university environment. The high intensity of the drive at the University as a result of the scheduling pattern of lectures, of course, followed by the high emissions produced by vehicles are used. The absence of the scheduling pattern lecture addressing impacts on the environment will certainly will confuse this environment with emissions continue discarded by humans. By incorporating the concept of constraint programming with a barrier that consider the impact on the environment in the course scheduling is expected to reduce vehicle emissions college participants. Department of Civil Engineering, as the oldest and largest department in the Faculty of Engineering, University of Diponegoro with an average number of 280 students each object in the application of his generation into the design of our proposed algorithm because it has the most number of vehicles compared to other departments in the Faculty of Engineering. The results of the application of this algorithm, is able to reduce the amount of emissions by 50\% for the class of 2011 and 2010 and even 66.6\% for the class of 2009 students.
\end{abstract}

Keywords: course scheduling; constraint programming; emission

\section{Pendahuluan}

Penjadwalan merupakan bagian terpenting dalam hidup manusia yang berfungsi untuk mengatur setiap kegiatan manusia pada waktu yang telah ditentukan secara sistematis. Menurut Pinedo (2008), penjadwalan adalah proses pengambilan keputusan yang digunakan secara teratur di banyak industri manufaktur dan jasa, yang berkaitan dengan alokasi

\footnotetext{
${ }^{*}$ Penulis Korespondensi. email: sriyanto.st.mt@gmail.com
}

Jurnal Teknik Industri, Vol. X, No. 2, Mei 2015 sumber daya untuk tugas selama masa waktu tertentu dan tujuannya adalah untuk mengoptimalkan satu atau lebih tujuan. Beragam aktifitas penjadwalan telah diaplikasikan dalam berbagai kegiatan manusia, tidak terkecuali penjadwalan yang diterapkan dalam kegiatan akademis seperti penjadwalan kuliah dan penjadwalan sekolah. Namun demikian, penjadwalan kuliah terbilang lebih rumit bila dibandingkan dengan penjadwalan sekolah karena memiliki lebih banyak batasan seperti ruang dan jam.

Dalam penelitian yang dilakukan oleh Sudano dan Rizha Amelia (2011), menyatakan bahwa kualitas 

1. Kerampingan kurikulum

Untuk mata kuliah dengan semester yang sama waktunya berdekatan

2. Gedung berbeda

Sebisa mungkin untuk gedung yang berbeda terdapat jeda waktu untuk perpindahan mahasiswa

3. Hari yang kosong

Sebisa mungkin ada hari yang kosong bagi mahasiswa untuk istirahat atau melakukan kegiatan lainnya.

Dengan adanya ecological constraint dalam engineering, dimungkinkan akan dihasilkan jawaban dari pertanyaan-pertanyaan fundamental. Pendekatan ekologi terhadap engineering harus melihat pada keadaan dan respon alam secara sistematis, kontinyu, dan kumulatif (Schulze, 1996). Untuk ecological constraint atau pembatas yang memperhatikan dampak terhadap lingkungan dalam penelitian ini merupakan pengembangan dari soft constraint yang lebih mengarah untuk menekan penggunaan kendaraan bermotor di lingkungan universitas yang dapat digunakan sebagai nilai tambah dalam perencanaan penjadwalan kuliah.

Constraint programming: Constraint programming adalah suatu metode yang muncul untuk mendeskripsikan deklarasi dan penyelesaian masalah yang efektif dari permaslahan yang besar, yang umumnya berupa kombinasi terutama pada bagian perencanaan dan penjadwalan.

Bermacam-macam pembatas belakangan ini muncul sebagai wilayah penelitian yang mengkombinasikan penelitian-penelitian dari sejumlah bidang, termasuk Artificial Intelligence, bahasa pemrograman, Symbolic Computing dan Computational Logic. Jaringan pembatas dan permasalahan pemuasan pembatas telah dipelajari dalam Artificial Intelligence sejak tahun tujuh puluhan. Penggunaan secara sistematik pada pembatas dalam pemrograman kemudian diterapkan di tahun delapan puluhan. Dalam constraint programming, proses pemrograman terdiri dari generation of requirements (pembatas) dan juga solusi atas kebutuhan tersebut, dengan pemecahan pembatas khusus (Bartak, 1999).

Pada dasarnya, constraint satisfaction hanya digunakan untuk menemukan solusi yang layak untuk tiap permasalahan. Bagaimanapun juga, struktur constraint satisfaction, ketika tertanam dalam framework yang lebih rumit, dapat diaplikasikan ke dalam permasalahan optimasi dengan baik.

Domain Reduction: Domain reduction adalah aplikasi langsung dari unary constraint $\mathrm{c}(\mathrm{x})$ kepada variabel $x$. Sebagai contoh, jika $\mathrm{x}$ adalah sebuah integer variable dengan domain $[0,10]$ dan $\mathrm{c}$ adalah $\mathrm{x}$ $>3$, maka domain dari x menjadi $[4,10]$.

Constraint propagation: Constraint propagation adalah suatu perambatan (propagation) dari perubahan dalam domain variabel ke domain pada variabel lainnya yang terhubung oleh suatu constraint. Sebagai contoh, jika $\mathrm{x}$ dan $\mathrm{y}$ adalah integer variable dengan

Jurnal Teknik Industri, Vol. X, No. 2, Mei 2015 domain asal $[0,10]$, dan sebuah constraint $\mathrm{x} \leq \mathrm{y}-3$ ditambahkan, maka perambatan pembatas bawah dari $\mathrm{x}$ ke y dapat dilakukan dengan cepat yaitu menjadikan domain y menjadi $[3,10]$ dan perambatan pembatas atas dari y ke $\mathrm{x}$ menjadi [0,7]. Lebih jauh, jika constraint $\mathrm{x}>3$ ditambahkan kemudian, penurunan domain x menjadi [4,7], pembatas bawah yang baru dirambatkan ke domain y yang menjadi $[7,10]$. Adapun secara ringkas langkah-langkah tersebut dapat dilihat pada Tabel 1.

Tabel 1. Contraint Propagation

\begin{tabular}{l|c|}
\hline Operation & Constraint graph \\
\hline $\begin{array}{l}\text { Define } x \text { and } y . \\
y \in[0,10]\end{array}$ & $y \leq[0,10]$ \\
\hline $\begin{array}{l}\text { Add } x \leq y-3 ; \\
\text { propagate. }\end{array}$ & $x \in[0,7]$ \\
\hline $\begin{array}{l}\text { Add } x>3 ; \\
\text { reduce } x, \\
\text { propagate. }\end{array}$ & $x \in[4,7]$ \\
\hline
\end{tabular}

Emisi gas buang: Emisi gas buang adalah sisa hasil pembakaran bahan bakar di dalam mesin pembakaran dalam, mesin pembakaran luar, mesin jet yang dikeluarkan melalui sistem pembuangan mesin. Menurut Zhongan dalam Tarigan (2009), emisi kendaraan bermotor di jalan disebabkan 3 faktor yaitu volume total kendaraan bermotor; karakteristik kendaraan bermotor; kondisi umum lalu lintas saat itu.

Adapun formulasi dasar yang diajukan untuk mengestimasi emisi dengan memakai emisi faktor adalah sebagai berikut (Tarigan, 2009):

Emission $(\mathrm{g})=$ emission factor $(\mathrm{g} / \mathrm{km}) *$ Vehicle kilometers traveled $(\mathrm{km})$

Sedangkan persamaan yang digunakan untuk menghitung beban emisi $\mathrm{CO}$ dan $\mathrm{CO} 2$ menurut Guttikunda (2008) dalam penelitian yang dilakukan oleh Eldewisa dan Driejana (2008) sebagai berikut :

- Pendekatan kecepatan kendaraan

Emisi (ton/tahun) = Jumlah Kendaraan x Jarak tempuh ( $\mathrm{km} /$ tahun) $\mathrm{x}$ faktor emisi $(\mathrm{gm} / \mathrm{km}) \times 10-6$ (ton/gm)

- Pendekatan konsumsi bahan bakar

Emisi (ton/tahun) = konsumsi bahan bakar (lt/tahun) $\mathrm{x}$ fuel economy $(\mathrm{km} / \mathrm{lt}) \mathrm{x}$ faktor emisi $(\mathrm{gm} / \mathrm{km}) \times 10-6$ (ton/gm)

Pada persamaan dengan pendekatan kecepatan kendaraan, variabel kecepatan digunakan dalam perhitungan nilai faktor emisi. Adapun faktor emisi kendaraan yang ada dalam rumus di atas telah ditentukan dalam penelitian yang dilakukan oleh Intergovernmental Panel on Climate Change suatu badan ilmiah internasional yang berada di bawah naungan Perserikatan Bangsa- Bangsa sebagaimana tampak pada Tabel 2. 


\begin{tabular}{lcccccc}
\hline \multirow{2}{*}{ Tipe kendaraan/ bahan bakar } & \multicolumn{7}{c}{ Faktor emisi (gram/liter) } \\
\cline { 2 - 7 } & $\mathrm{NO}_{\mathrm{x}}$ & $\mathrm{CH}_{4}$ & NMVOC & $\mathrm{CO}$ & $\mathrm{N}_{2} \mathrm{O}$ & $\mathrm{CO}_{2}$ \\
\hline Bensin: & & & & & & \\
Kendaraan penumpang & 21.35 & 0.71 & 53.38 & 462.63 & 0.04 & 2597.86 \\
Kendaraan niaga kecil & 24.91 & 0.71 & 49.82 & 295.37 & 0.04 & 2597.86 \\
Kendaraan niaga besar & 32.03 & 0.71 & 28.47 & 281.14 & 0.04 & 2597.86 \\
Sepeda motor & 7.12 & 3.56 & 85.41 & 427.05 & 0.04 & 2597.86 \\
\hline Diesel: & & & & & & \\
Kendaraan penumpang & 11.86 & 0.08 & 2.77 & 11.86 & 0.16 & 2924.90 \\
Kendaraan niaga kecil & 15.81 & 0.04 & 3.95 & 15.81 & 0.16 & 2924.90 \\
Kendaraan niaga besar & 39.53 & 0.24 & 7.91 & 35.57 & 0.12 & 2924.90 \\
Lokomotif & 71.15 & 0.24 & 5.14 & 24.11 & 0.08 & 2964.43 \\
\hline LPG: & & & & & & \\
Kend penumpang (Eropa) & 34.62 & 0.77 & 23.08 & 100.00 & 0.00 & 2500.00 \\
Kend penumpang (US) & 14.62 & 1.15 & 24.62 & 55.77 & 0.00 & 2426.92 \\
Kendaraan niaga besar & 13.85 & 1.15 & 19.62 & 58.46 & 0.00 & 2426.92 \\
\hline LNG: & & & & & & \\
Kendaraan penumpang & 13.52 & 22.42 & 3.20 & 25.62 & 0.00 & 1996.44 \\
Kendaraan niaga besar (bensin) & 12.46 & 21.71 & 3.20 & 25.98 & 0.00 & 1996.44 \\
Kendaraan niaga besar (solar) & 45.55 & 19.93 & 3.91 & 15.66 & 0.00 & 1996.44 \\
\hline Methanol/Ethanol: & & & & & & \\
Kend penumpang (M85) & 5.07 & 0.27 & 6.67 & 31.73 & 0.00 & 1858.67 \\
Kendaraan niaga besar (M100) & 8.00 & 0.27 & 2.93 & 8.00 & 0.00 & 1858.67 \\
\hline
\end{tabular}

Tabel 2. Faktor Emisi Kendaraan (Fitri, 2009)

\section{Hasil dan Pembahasan}

Dengan memperhatikan konsep domain reduction dan constraint propagation pada constraint programming. Penyusunan algoritma penjadwalan terbagi atas dua tahapan, yakni construction dan improvement. Pada tahapan pertama, algoritma dirancang untuk sedemikian rupa mendekati hasil yang diharapkan tanpa melewati pembatas yang telah ditetapkan, sedangkan untuk tahapan kedua adalah tahapan untuk mengembangkan jadwal sehingga dapat mencapai hasil yang optimum, dalam hal ini adalah minimasi jumlah frekuensi. Adapun algoritma tersebut adalah sebagai berikut:

\section{Algoritma construction}

1. Hitung emisi masing-masing kelas

Hitung $I, I=\left(F_{T} \times T_{K} / O_{T}+F_{B} \times B_{K} / O_{B}\right) x$ jarak

2. Pilih kelas dengan jumlah emisi terbesar

Pilih $K$ dengan I terbesar

3. Pilih MK dengan jumlah SKS terbesar Pilih $M$ dengan $S(M)$ terbesar

4. Identifikasi status MK tersebut seperti angkatan yang mengambil, jumlah SKS, jumlah peserta dan jumlah kendaraan pada MK tersebut Identifikasi $M$

5. Tentukan hari untuk plotting MK tersebut Tentukan H untuk plotting $M$ tersebut

6. Hitung jumlah SKS kumulatif untuk kelas yang sama dengan kelas MK tersebut.

- Jika lebih dari 6 SKS, lanjut ke langkah berikutnya

- Jika kurang dari 6 SKS, lanjut ke langkah kedelapan

Jurnal Teknik Industri, Vol. X, No. 2, Mei 2015
Hitung $\sum S(M)$, jika $\sum S(M) \leq 6$ lanjut langkah berikutnya,

Jika tidak lanjut ke langkah kedelapan

7. Ulangi langkah kelima, untuk hari $\mathrm{h}+1$ dan berhenti jika tidak ada lagi hari berikutnya.

Ulang langkah kelima untuk hari $h+1$ sampai tidak ada hari berikutnya lagi

8. Identifikasi slot yang kosong untuk jam dan ruang sesuai dengan pembatas berikut

- Jumlah mahasiswa tidak melebihi kapasitas ruangan dengan selisih yang paling sedikit. $P(R) \geq A(K)$

- Jumlah kendaraan kumulatif pada kolom waktu yang sama tidak melebihi kapasitas lahan parkir

$T(K) \leq 400$ dan $B(K) \leq 20$

- Tidak terdapat jeda untuk MK yang diambil oleh kelas yang sama.

$\sum_{h \in H} \sum_{j \in J} X_{K_{M R H J}}-\sum_{h \in H} \sum_{j \in J} X_{K_{M R H J}}=$ $0, \forall k \in K, \forall h \in H$

- Tidak terdapat jam yang sama untuk kelas yang sama

$\sum_{k \in K} \sum_{m \in M_{K}} X_{K M R H J} \leq 1, \forall h \in H, \forall j \in$ $J, \forall r \in R$

- Tidak terdapat ruang yang sama untuk MK yang berbeda

$\sum_{k \in K} \sum_{r \in R} X_{K M R H J} \leq 1, \forall h \in H, \forall j \in J, \forall m \in$ $M$

- Jumlah slot memenuhi jumlah SKS pada MK tersebut

$\sum_{h \in H} \sum_{j \in J} \sum_{r \in R} X_{K M R H J} \geq S(M)$

* Jika memenuhi lanjut ke langkah berikutnya 
* Jika tidak memenuhi ulang langkah kelima untuk hari $\mathrm{h}+1$ dan berhenti jika tidak ada lagi hari berikutnya.

9. Plot MK untuk slot tersebut.

10. Ulangi langkah ketiga sampai semua $M$ selesai diplotkan.

11. Ulangi langkah kedua sampai semua $\mathrm{K}$ telah selesai diplotkan.

\section{Algoritma improvement}

1. Hitung Emisi masing masing kelas

Hitung $I, I=\left(F_{T} \times T_{K} / O_{T}+F_{B} \times B_{K} / O_{B}\right) x$ jarak

2. Pilih kelas dengan urutan berdasar jumlah emisi terbesar

Pilih $K$ dengan I terbesar

3. Identifikasi jumlah SKS per hari.

- Jika terdapat jumlah SKS per hari yang kurang dari sama dengan 4 SKS lanjut ke langkah berikutnya

- Jika tidak terdapat jumlah SKS per hari yang kurang dari sama dengan 4 SKS, maka ulangi langkah kedua sampai semua kelas telah teridentifikasi.

Hitung $\sum S(M)$, Jika $\sum S(M) \leq 4$, lanjut kelangkah berikutnya

Jika tidak, ulang langkah kedua untuk semua $K$

4. Identifikasi jumlah hari dimana terdapat kondisi yang sesuai pada langkah ketiga

- Jika jumlah hari lebih dari sama dengan 2, maka lanjutkan ke langkah berikutnya

- Jika jumlah hari kurang dari 2, ulangi langkah kedua sampai semua kelas teridentifikasi.

Hitung $\sum H_{S(M)}$, jika $\sum H_{S(M)} \geq 2$ lanjut ke langkah berikutrnya

Jika tidak ulangi langkah kedua untuk semua $K$

5. Identifikasi $M$ yang memenuhi kondisi pada langkah ketiga dan keempat

6. Kombinasikan $\mathrm{M}$ pada langkah kelima berdasar pembatas jumlah SKS maksimal adalah 6 .

- Jika jumlah kombinasi lebih sedikit daripada jumlah hari yang diidentifikasi pada langkah keempat, lanjut ke langkah berikutnya.

- Jika jumlah kombinasi lebih besar atau sama dengan jumlah hari yang diidentifikasi pada langkah keempat, ulangi langkah kedua sampai semua kelas teridentifikasi.

Kombinasikan $M_{H S(M)}$ dengan pembatas $S(M) \leq$ 6

Jika $\sum$ kombinasi $<\sum H_{S(M)}$, lanjut ke langkah berikutnya

Jika tidak, ulang langkah kedua untuk semua kelas.

7. Tarik kembali $\mathrm{M}$ hasil kombinasi tersebut dari jadwal sebelumnya.

8. Pilih kombinasi dengan jumlah SKS terbanyak terlebih dahulu.

Pilih kombinasi dengan $\sum S(M)$ terbesar

9. Pilih hari dengan jumlah SKS terkecil untuk kelas tersebut

Pilih $H$ dengan $\sum S(M)$ terkecil

Jurnal Teknik Industri, Vol. X, No. 2, Mei 2015
10. Identifikasi slot yang tersedia sesuai dengan pembatas berikut ini

- Jumlah mahasiswa tidak melebihi kapasitas ruangan dengan selisih yang paling sedikit.

$$
P(R) \geq A(K)
$$

- Jumlah kendaraan kumulatif pada kolom waktu yang sama tidak melebihi kapasitas lahan parkir

$$
T(K) \leq 400 \text { dan } B(K) \leq 20
$$

- Tidak terdapat jam yang sama untuk kelas yang sama

$\sum_{k \in K} \sum_{m \in M_{K}} X_{K M R H J} \leq 1, \forall h \in H, \forall j \in$ $J, \forall r \in R$

- Tidak terdapat ruang yang sama untuk MK yang berbeda

$$
\sum_{k \in K} \sum_{r \in R} X_{K M R H J} \leq 1, \forall h \in H, \forall j \in J, \forall m \in
$$
$M$

- Jumlah slot memenuhi jumlah SKS pada MK tersebut

$$
\sum_{h \in H} \sum_{j \in J} \sum_{r \in R} X_{K M R H J} \geq S(M)
$$

* Jika memenuhi semua pembatas, plot pada slot tersebut, dan lanjut ke langkah berikutnya.

* Jika tidak ada yang memenuhi salah satu pembatas, ulangi langkah kesembilan untuk hari berikutnya dan berhenti jika tidak ada lagi tabel hari selanjutnya.

11. Plot pada slot tersebut

12. Ulangi langkah kedelapan sampai semua kombinasi selesai diplotkan

13. Ulangi langkah kedua sampai semua $\mathrm{K}$ telah teridentifikasi.

Adapun hasil dari penjadwalan dengan menggunakan algoritma tersebut mampu mengurangi jumlah frekuensi sebanyak 50\% untuk 2 angkatan yakni 2010 dan 2011, sedangkan untuk angkatan 2009 bahkan mampu mengurangi sampai $66,6 \%$.

\section{Kesimpulan}

Adapun algoritma yang dihasilkan berdasarkan konsep constraint programming dalam penyusunan jadwal kuliah ini terbagi menjadi dua tahapan yakni algoritma construct yang pertama dan yang kedua adalah algorima improve

Algoritma construction bertujuan untuk membangun jadwal kuliah baru.

Algoritma improvement bertujuan untuk mengembangkan jadwal yang telah dibangun menjadi lebih baik

Penggunaan algoritma penjadwalan kuliah yang dihasilkan berdasarkan konsep constraint programming mampu menurunkan emisi di Teknik Sipil Universitas Diponegoro sebesar 50 untuk angkatan 2011 dan 2010, sedangkan untuk 2009, bahkan mencapai $66,6 \%$.

\section{Daftar Pustaka}

Bartak, R. 1999, Constraint Programming: In Pursuit of The Holy Grail, Proceedings of the Week of 
Doctoral Students (WDS99), Part IV, Prague, Pp.555-564.

Burke, E dan Jackson, K. 1997. Automated University Timetabling: The State of The Art. University of Nottingham, UK

Eldewisa, Zahra dan Driejana. 2008. Perbandingan Estimasi Beban Emisi CO dan CO2 Dengan Pendekatan Konsumsi Bahan Bakar Dan Kecepatan Kendaraan (Studi Kasus : Bunderan Cibiru-Lembang). ITB: Bandung

Fitri, Gustina. 2009, Tingkat Polusi Udara Dari Emisi Gas Buang Kendaraan Bermotor Berdasarkan Volume Lalu Lintas (Studi Kasus : Simpang Empat Bersinyal Kota Lhokseumawe), Jurnal Reaksi, Vol 7, No 16, Desember 2009 ISSN 1693-248X.
Massodian, S. Dan Esteki, A. 2008. A Hybrid Genetic Algorithm for Curriculum Based Course Timetabling. The Second International Timetabling Competition 2007.

Pinedo, Michael L. 2008. Scheduling Theory, Algorithms, and Systems Third Edition. New York:Prentice Hall.

Schulze, Peter C. 1996. Engineering within Ecological Constraints. Washington, D.C: National Academy Press.

Sudano, Titik Istirokhatun dan Rizha Amelia.2012. Hantu Itu Bernama Polusi Udara. UNDIP: Semarang

Tarigan, Abner 2009. Estimasi Emisi Kendaraan Bermotor Di Beberapa Ruas Jalan Kota Medan, Thesis, USU Repository. 